\title{
The Study of Teaching Reform of Higher Mathematics Based on OBE
}

\author{
Zaibin Su \\ Department of mathematics \\ Heilongjiang institute of technology \\ Harbin, China
}

\author{
Haiyan Yuan \\ Department of mathematics \\ Heilongjiang institute of technology \\ Harbin, China
}

\begin{abstract}
This paper aims at the teaching reform of higher mathematics of Heilongjiang institute of technology whose training goal is training applied undergraduate talents. It introduces the OBE education mode, discusses the significance of the OBE project teaching method in the teaching of higher mathematics, and discusses the reformation in the teaching of higher mathematics: the teaching content reformation, teaching method reformation, course assessment reformation and course feedback reformation. It emphasizes cultivation of students' mathematical thinking and application ability to solve practical problems.
\end{abstract}

Keywords-Higher mathematics; OBE; Student subject; Online course

\section{THE OBE IDEA}

\section{A. The Development of OBE Concept}

Outcome-based education (OBE), one of the three core concepts of Engineering education, was first proposed by Spady [1] in 1981. The so-called results, its focus is not on the student's score, but on the students' ability after the learning process. At present, OBE has formed a relatively complete theoretical system, which is still regarded as the key to pursuing high quality education. The American Association for Engineering Education Certification (ABET) applies the concept of OBE throughout the certification standards of Engineering education.

\section{OBE stresses the following five questions: [2]}

(1) What do we want the students to achieve?

(2) Why should we allow students to achieve such learning results?

(3) How can we effectively help students achieve these learning outcomes?

(4) How do we know that students have achieved these achievements?

(5) How do we ensure that students can achieve these learning outcomes?

This paper is supported by the education and teaching reform project of Heilongjiang institute of technology (JG201817 and JG 2017017)
There are four in the implementation of OBE: [3]:

(1) To have a clear learning goal: Curriculum teaching should focus on the ability that students can really have at the end of the whole learning process, not the curriculum activities of a semester or a school year.

(2) A variety of teaching methods to ensure learning opportunities: Teachers should be more flexible to meet the individual needs of students, and give students the opportunity to verify what they have learned, and to check their learning results.

(3) Set reasonable expectation goals: Teachers should regard students' learning process as a high-level challenge to self-realization, set a high standards, and expect students to achieve self-realization.

(4) Return to the basic curriculum design: Curriculum and instructional design should return to the ability students achieve, with the outstanding performance of students as the ultimate goal of teaching.

No matter what OBE emphasizes or the principle of implementation always embodies the basic concept of studentcentered, these requires that the teaching model of studentcentered should be established in engineering education.

\section{B. The Advantages of $O B E$}

(1) OBE emphasizes the results not the processes. The traditional education curriculum teaching strictly follows the prescribed process, unifies the teaching time, the content, the way and so on. Teaching progress is presupposed on the assumption that most students can complete their studies. If students fail to complete their studies within the prescribed time, they will be regarded as failing to meet the teaching requirements. OBE's goals, curriculum, teaching materials, evaluation and graduation requirements are all focused on the results. OBE emphasizes that students have clear goals and expected performance from the beginning of learning, students know what they expect to learn, and teachers know more about how to help students learn. Therefore, students can gradually achieve their goals according to their own learning experience, learning style and learning progress, and all students have the opportunity to succeed.

(2) $O B E$ expanded opportunities. Traditional education strictly enforces the prescribed learning procedures, just like 
putting students into the same speed and manner of operation of the "car", limiting the chances of success of students. OBE emphasizes expanding opportunities, that is, to modify, adjust and resiliently respond to students' learning requirements in time, guided by learning outcomes and based on Evaluation results. "Expansion" means improving learning content, mode and time instead of prolonging learning time.

(3) $O B E$ emphasizes the knowledge integration. Traditional education emphasizes the curriculum system, which actually cuts the knowledge structure into curriculum units. Each course becomes a relatively independent and welldefined knowledge unit. The relationship between these knowledge units is weakened. Students' learning is often "see trees, not forests". OBE emphasizes the integration of knowledge, which is a reverse design based on the knowledge (ability) structure, so that the curriculum system supports the knowledge structure, so that each course of learning and knowledge (ability) structure correspond, and ultimately enable students to achieve peak results.

(4) OBE emphasizes the dominant position of students. Traditional education takes teacher as the center, and they decide what is taught and how to teach. Students should accept the arrangement of teachers passively. OBE emphasizes student-centered, teachers should make good use of demonstration, diagnosis, evaluation, feedback and constructive intervention strategies to guide and assist students to achieve the desired results.

(5) OBE emphasizes cooperative learning rather than competitive learning. Traditional education pays too much attention to competitive learning, distinguishes or labels students by grading, and places the relationship between teachers and students, students and students in a competitive environment. In such an environment, it is impossible to establish a harmonious and interactive relationship between successful learners and failure learners. OBE emphasizes cooperative learning, transforming competition between students into self-competition, that is, to let students continue to challenge themselves, to achieve the peak results of cooperative learning. Through teamwork, collaborative learning and other ways, so that the learning ability of the stronger becomes stronger, the weaker is promoted.

(6) OBE has set up a reasonable evaluation mechanism. Traditional education emphasizes comparative evaluation. Most courses have a lot of teaching objectives. Traditional educational evaluation methods are single. Different grades of students are evaluated only by examining their performance. OBE emphasizes self-evaluation, achieving consistency between expected results and evaluation, and setting up a series of evaluation items. These evaluations include the cultivation of students' professional ability, including the evaluation of various qualities and abilities, making the evaluation more authentic and effective.

\section{SOME REFORMS IN HIGHER MATHEMATICS TEACHING}

\section{A. Choose the Teaching Objectives}

The goal of teaching is the learning outcomes, which is both the end and the starting point of OBE. The determination of the learning outcomes relates to the requirements and expectations of educational stakeholders, including the government, schools and employers, as well as students, teachers and students' parents.

OBE lays particular emphasis on what students have learned rather than what teachers have taught, especially on the output of the teaching process rather than its input. We determine the teaching objectives and content of the students' expectations by through a series of studying, such as social surveys, a visit to departments, and a return visit to university graduates which ensure that the teaching objectives can be achieved and meet the needs of students' development.

(1) Inspire students with problem-based learning[5,6]. In the process of teaching, teachers consciously put forward some practical problems with professional background before the class, so that the students can use the network or consult information to solve them in groups. In class, the students give the solution of the problem in the way of group talk and evaluation. These questions not only mobilized the enthusiasm of students, but also trained problem-solving ability of students.

(2) Using various ways to promote teaching. Use various popular teaching resources [4] such as micro-lessons, curtain lessons, etc., or send better teaching videos to students, so that students can watch and learn from them. The intuitive teaching which is the complementary to classroom teaching is vivid and intuitive.

(3) Reform of evaluation methods. OBE's teaching evaluation focuses on learning outcomes[7]. The establishment of multiple and echelon evaluation criteria can reasonably evaluate the achievement of learning outcomes.

\section{a) Examination of theoretical knowledge}

Higher mathematics is a mathematics course. Doing exercises is one of the most direct ways to learn it well. In many textbooks, the process of theoretical deduction can not be understood simply by thinking, but must be done practically. It is difficult to understand the contents of the book without doing a certain amount of exercises. Through the examination of the theoretical part, students can deeply understand these numerical methods and principles, and lay a good theoretical foundation for solving practical problems.

\section{b) Practical ability assessment}

Give students some practical problems, such as giving the distribution network of logistics, matching chemical equation equality which requires students to use the knowledge of higher mathematics to solve practical problems [8-10]. This is an effective method which urges students to hammer out textbook knowledge and apply it to practical problems. It can not only deepen students' understanding of textbook content, but also cultivate students' ability to solve practical problems 
with mathematical thinking, and achieve the purpose of applying learning.

\section{c) Online learning assessment}

While giving students online classroom videos, they are asked to answer some questions online [11, 12]. By through the students' online answers and the monitoring of students' video watching points repeatedly, we can keep abreast students' mastery of knowledge, the mistakes and weak knowledge of students.

\section{CONCLUSION}

Good results will not be bad. The unprecedented enthusiasm of the 2017 students in our school to study higher mathematics has strengthened our determination and confidence to continue to do, although it requires a lot of effort and hard work, it is worthwhile to work hard for improving the teaching effect. It is a long-term practice process that teachers explore better teaching mode on the basis of continuing to implement OBE hybrid teaching mode. Students' interest in learning is often closely related to teachers' personality charm and the atmosphere of the school. The teachers' knowledge, elegant teaching attitude, cadence, harmonious campus environment, good style of study and so on will leave a deep imprint on students' hearts. The influence of these aspects is much better than that of formal theoretical education. Therefore, the success of curriculum reform requires the careful study of teachers, the active cooperation of students, and the support of schools.

\section{REFERENCES}

[1] W. Spady, Choosing Outcomes of Significance [J]. Educational Leadership, 1994 (51) 6: 18-22.

[2] Z. Li, Adapt to certification requirements, promote engineering education and teaching reform [J].Teaching in Chinese universities, 2014 (6): 9-16.( In Chinese)

[3] Z. Li, Analysis of the student centered concept of Engineering Education Accreditation [J]. Higher education in China, 2014 (21): 19-22.( In Chinese)

[4] J. Zhao, B. Wu, Some discussions on the teaching of numerical analysis; [J]; University mathematics;2005(3) 03: 30-32.( In Chinese)

[5] Who do project based learning [EB/OL]. http://www. pblmm. k12. ca.us/pblguide/ why PBL. Html. 2001-10-23.

[6] J. Liu, Z. Zhong, The study of Problem-based learning (PBL) [J]. Foreign education research, 2002 (29) 11:19-22.( In Chinese)

[7] L.Xu, Exploration of higher mathematics teaching reform under the training mode of applied talents [J]. Science and technology Wen hui, 2015, (310):81-83.( In Chinese)

[8] J. Clerk Maxwell, A Treatise on Electricity and Magnetism, 3rd ed., vol. 2. Oxford: Clarendon, 1892, pp.68-73.

[9] I.S. Jacobs and C.P. Bean, "Fine particles, thin films and exchange anisotropy,” in Magnetism, vol. III, G.T. Rado and H. Suhl, Eds. New York: Academic, 1963, pp. 271-350.

[10] R. Nicole, “Title of paper with only first word capitalized,” J. Name Stand. Abbrev., in press.

[11] Y. Yorozu, M. Hirano, K. Oka, and Y. Tagawa, "Electron spectroscopy studies on magneto-optical media and plastic substrate interface,” IEEE Transl. J. Magn. Japan, vol. 2, pp. 740-741, August 1987 [Digests 9th Annual Conf. Magnetics Japan, p. 301, 1982].

[12] M. Young, The Technical Writer's Handbook. Mill Valley, CA: University Science, 1989. 